\title{
Estimation of malaria transmission in high-risk provinces of Morocco
}

C. Faraj, ${ }^{1}$ E. Adlaoui, ${ }^{1}$ M. Rhajaoui ${ }^{1}$ and M. Lyagoubi ${ }^{1}$

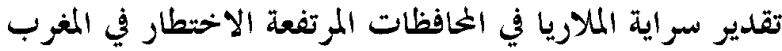

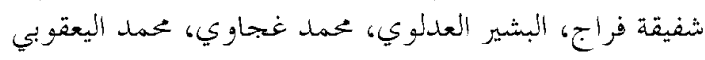

$$
\begin{aligned}
& \text { الحلاحسة: تحم رصد مستوى سراية الملاريا بالمتصورات النشيطة في أربع محافظات مرتفعة الاختطار في المغرب. وقدات }
\end{aligned}
$$

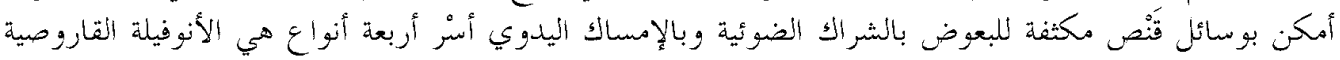

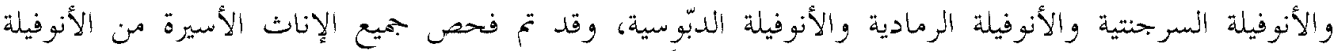

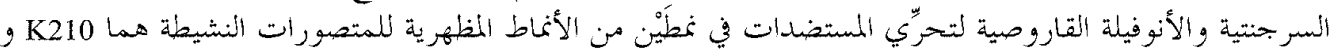

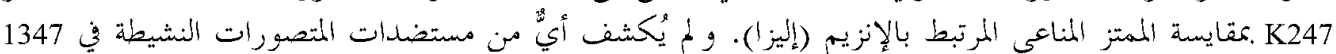

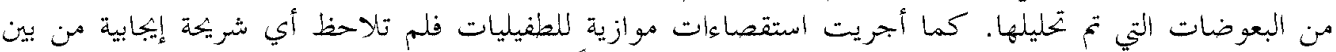

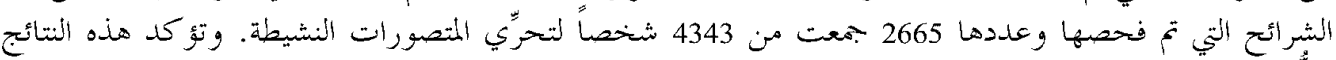

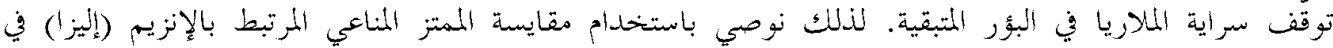

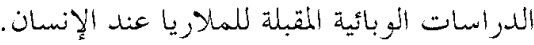

ABSTRACT The malaria transmission level of Plasmodium vivax was monitored in four high-risk provinces in Morocco. Intensive mosquito collection by light traps and manual catches resulted in the capture of four species: Anopheles labranchiae, An. sergenti, An. cinereus, and An. claviger. All An. sergenti and An. labranchiae females collected were tested for the presence of two phenotypes of $P$. vivax (PVK210 and PVK247) antigen by enzyme-linked immunosorbent assay (ELISA). No $P$. vivax antigen was detected in 1347 mosquitoes analysed. A parallel parasitological investigation was conducted. Of 2665 slides examined from a population of 4343 people for detection of $P$. vivax, no slide was positive. The results confirm the break in malaria transmission in residual foci. The use of ELISA is recommended in future epidemiological studies of human malaria.

Evaluation de la transmission du paludisme dans des provinces à haut risque au Maroc RESUME Le taux de transmission du paludisme par Plasmodium vivax a fait l'objet d'une surveillance dans quatre provinces à haut risque au Maroc. Une capture intensive de moustiques faite à la main et à l'aide de pièges lumineux a permis de collecter quatre espèces : Anopheles labranchiae, An. sergenti, An. cinereus et An. claviger. Toutes les femelles $A n$. sergenti et $A n$. labranchiae capturées ont été soumises à des tests pour rechercher la présence de deux phénotypes d'antigène de $P$. vivax (PVK210 et PVK247) par la méthode immuno-enzymatique (ELISA). Aucun antigène de $P$. vivax n'a été détecté chez 1347 moustiques analysés. Une enquête parasitologique parallèle a été menée. Sur les 2665 lames examinées provenant de 4343 personnes pour rechercher la présence de $P$. vivax, aucune n'était positive. Les résultats ont confirmé l'arrêt de la transmission du paludisme dans les foyers résiduels. L'utilisation de la méthode ELISA est recommandée dans les futures études épidémiologiques du paludisme humain.

${ }^{1}$ Department of Parasitology, National Institute of Hygiene, Rabat, Morocco.

المجلة الصحية لشرق المتوسط، منظمة الصحة العالمية، المجلد التاسع، العدد ع، ب... 


\section{Introduction}

In Morocco, a programme to eliminate Plasmodium vivax malaria was started in 1998. So far, the massive investment in malaria control by the programme has brought about rapid regression of the number of cases. In 1999, 17 cases were registered in the province of Khouribga. In 2000 , there were only 3 reported cases in the country, 2 in Khouribga province and 1 in Taounate province. In 2001 no malaria cases were registered. Nevertheless, because of the very frequent atypical clinical forms of $P$. vivax, its long latency period, which can exceed 5 years [1], and the presence of the vector in high-risk areas, malaria transmission is always a possibility in these areas. It was crucial, therefore, to be able to confirm the interruption of transmission and to monitor the situation by a mass screening for sporozoites of Anopheles spp. by using, for the first time in Morocco, an enzyme-linked immunosorbent assay (CS-ELISA). This technique offers several advantages, the main ones being that it is species-specific and it can detect sporozoites in pooled samples [2]. Processing pooled specimens is a fast, efficient and economic method for determining sporozoite prevalence, especially in areas of low malaria endemicity where dissections may not be conducted routinely $[3,4]$.

This study was designed to determine the level of malaria transmission by measuring sporozoite infection rates in fieldcollected anopheline mosquitoes from residual foci of malaria in Morocco.

\section{Methods}

\section{Study area}

The study was conducted in 2 regions of Morocco that are classified according to epidemiological data as high-risk zones: Al
Hoceima, Chefchaouen and Taounate in the northern region and Khouribga in the central region. Mosquitoes were collected in the 2 villages of each province where the last malaria cases were recorded (a total of 8 villages):

- Azib Bouflou (5 cases in 1996) and Azib Jerou (16 cases in 1996) in Al Hoceima province;

- Imzouen (1 case in 1998) and Amzaourou (4 cases in 1998) in Chefchaouen province;

- Ouled Nsar (32 cases in 1998) and Tamloult (1 case in 2000) in Taounate province;

- Ait Abdeslam (1 case in 2000) and Ait Lamfadel (1 case in 2000) in Khouribga province.

Five villages of the 8, (Azib Bouflou, Azib Jerou, Imzouen, Amzaourou and Tamloult) are located in mountains; the terrain is very difficult and they are not easily accessible. The other 3 villages (Ouled Nsar, Ait Abdeslam and Ait Lamfadel) are located in valleys.

\section{Blood examination}

In parallel to the entomological investigation, a malaria prevalence survey was conducted in the same 8 villages following the criteria of the National Malaria Control Programme [5]. We examined $16 \%$ of the population by selective tracking (active and passive). Blood samples were taken twice a month from January to October 2002 from all persons presenting or having presented with fever. In addition, mass tracking was carried out at the beginning and end of the transmission period covering 90\%-95\% of the locality [cover rate $=($ No. of homes visited/No. of homes in the locality) $\times 100$ ]

All blood samples, consisting of thin smears and thick blood films, were stained with Giemsa stain and examined for Plasmodium parasites.

المجلة الصحية لشرق المتوسط، منظمة الصحة العالمية، المجلد التاسع، العدد ع، ب..ب 


\section{Mosquito sampling, conservation and identification}

Mosquitoes were collected in the 8 villages studied by 2 traditional sampling techniques, daytime resting catches and light trap catches [6], twice a month during the active malaria transmission season from May to October 2002. Indoor daytime resting collection was conducted inside 10 buildings (human dwellings and animal shelters) from 06:00 to 11:00 in each village (a total of 20 households per province). The criteria for house selection were based on their proximity to larval breeding sites. Light trap catches were carried out using 4 Centers for Disease Control light traps in each village.

All female anopheline mosquitoes collected were identified to species using the keys developed by Bruhnes et al. [7]. Only An. labranchiae and An. sergenti females were bisected into head-thorax and abdomen. The head-thoraxes were kept dry (stored individually in polypropylene micro centrifuge tubes with silica gel) and refrigerated at $4{ }^{\circ} \mathrm{C}$ until tested by ELISA specific for the presence of circumpsporozoite (CS) antigens for $2 P$. vivax phenotypes (VK210 and VK247) [2,8].

\section{Enzyme-linked immunosorbent assay}

The collected mosquitoes were divided into pools of up to 5 specimens. Pools were created taking into account species, collection site (province and village), collection date and collection method. The initial test was conducted with mixtures of the 2 monoclonal antibodies (VK210 and VK247) in a single plate. This combined approach caused no significant reduction in sensitivity of the individual assays [9].

The CS-ELISA was used according to the method described by Wirtz et al. with minimal modifications [2]. Briefly, pooled mosquitoes were triturated in $50 \mu \mathrm{L}$ block- ing buffer with Igepal 630 (IG-630) using a motorized pestle in $1.5 \mathrm{~mL}$ polypropylene microcentrifuge tubes. Additional blocking buffer was rinsed over the pestle into the microfuge tubes containing the mosquito triturate to bring the volume to $200 \mu \mathrm{L}$ per sample. The pestle was cleaned between samples by high-speed passes in beakers of phosphate-buffered saline (PBS)-Tween 20 and then dried to prevent contamination. Aliquots of mosquito triturate were frozen for later analysis. We incubated 96-well microtitre plates simultaneously with $50 \mu \mathrm{L}$ of each monoclonal antibody $(0.025 \mu \mathrm{g} / 50 \mu \mathrm{L}$ of PBS for VK210 and $0.05 \mu \mathrm{g} / 50 \mu \mathrm{l}$ of PBS for VK247) covered at room temperature overnight. The following morning the plate contents were aspirated and the wells filled with blocking buffer After 1 hour of incubation at room temperature, plates were washed 3 times again with PBS- $0.05 \%$ Tween 20, emptied and then $50 \mu \mathrm{L}$ of mosquito triturate was added to the respective wells. These were covered and after 2 hours of incubation at room temperature, well contents were aspirated, the plates were washed two times with PBS- $0.05 \%$ Tween 20 before the addition of horseradish peroxidase-conjugated monoclonal antibodies simultaneously for the two $P$. vivax phenotypes $(0.05 \mu \mathrm{g} / 50 \mu \mathrm{L}$ blocking buffer/well for VK210 and $0.01 \mu \mathrm{g} / 50 \mu \mathrm{L}$ blocking buffer/well for VK247). After 1 hour of incubation in the dark at room temperature, the plates were washed 3 times with PBS$0.05 \%$ Tween 20 , followed by addition of $100 \mu \mathrm{L} /$ well of substrate solutions. After stopping with $4 \mathrm{~N}$ sulfuric acid solution and 30 minutes of incubation in the dark, plates were read at $450 \mathrm{~nm}$ using an ELISA plate reader. Plates were covered during incubations to prevent evaporation. Positive and negative controls were run on each plate. Negative controls consisted of blocking buffer containing a laboratory-reared uninfected An. labranchiae mosquito. Positive

المجلة الصحية لشرق المتوسط، منظمة الصحة العالمية، المجلد التاسع، العدد ع، ب... 
controls consisted of synthetic $P$. vivax peptide. The normal optical density value was determined by calculating mean \pm 2 standard deviations of 7 negative controls. Cut-off scores for positive samples were determined as optical density values that were higher than mean +2 standard deviations for the negative controls.

\section{Results}

\section{Parasitological observations}

During the year 2002, blood samples were taken and examined from 2665 people of 4343 (total population of the 8 villages), corresponding to a yearly haematological examination rate of $61.4 \%$. The incidence of malaria over the study period was negative since no cases of malaria were detected in the 8 villages studied (Table 1).

\section{Anophelene infectivity}

A total of 5646 mosquitoes, 4295 An.cinereus (76\%), 1203 An sergenti (21\%), 144 An. labranchiae (3\%) and 4 An. claviger $(0.07 \%)$, were caught during
39 field missions in the 8 villages studied. From the 1347 An. labranchiae and An. sergenti collected, 302 mosquito pools containing from 1-5 specimens each were prepared and tested by CS-ELISA specific for the presence of CS antigens for the $2 P$. vivax phenotypes (VK210 and VK247). No $P$. vivax sporozoites were detected in the 302 mosquito pools (Table 2).

\section{Discussion}

The negative results obtained by CS-ELISA for the mosquitoes collected from the highrisk areas present a reliable indicator of the absence of the Anopheles vector in a large sample of the mosquito population in these zones. This cannot be taken as a confirmation of the absence of sprozoites circulating in the total population. When combined with the results of the parasitological investigation (absence of positive slides), however, the results confirm the absence of circulating Anopheles sporozoites during this year, and therefore confirm a break in

\begin{tabular}{|c|c|c|c|c|}
\hline Location & $\begin{array}{c}\text { Total } \\
\text { population }\end{array}$ & $\begin{array}{l}\text { No. of slides } \\
\text { examined }\end{array}$ & $\begin{array}{l}\text { Annual haematological } \\
\text { examination rate (\%) }\end{array}$ & $\begin{array}{l}\text { No of positive } \\
\text { slides }\end{array}$ \\
\hline \multicolumn{5}{|c|}{ Al Hoceima province } \\
\hline Azib Bouflou & 556 & 390 & 70 & 0 \\
\hline Azib Jerou & 504 & 434 & 86 & 0 \\
\hline \multicolumn{5}{|c|}{ Chefchaouen province } \\
\hline Imzouen & 215 & 75 & 35 & 0 \\
\hline Amzaourou & 179 & 423 & 236 & 0 \\
\hline \multicolumn{5}{|c|}{ Taounate province } \\
\hline Ouled Nsar & 402 & 588 & 146 & 0 \\
\hline Tamloult & 646 & 144 & 22 & 0 \\
\hline \multicolumn{5}{|c|}{ Khouribga province } \\
\hline Ait Lamfadel & 738 & 345 & 47 & 0 \\
\hline Ait Abdeslam & 1103 & 266 & 24 & 0 \\
\hline
\end{tabular}

المجلة الصحية لشرق المتوسط، منظمة الصحة العالمية، المجلد التاسع، العدد ؟، ب... 
Table 2 Circumsporozoite (CS) antigen enzyme-linked immunosorbent assay testing results of mosquitoes collected in 8 villages in Morocco from May to October 2002

\begin{tabular}{lcc}
\hline Species & No. tested & $\begin{array}{c}\text { No. with CS } \\
\text { antigen }\end{array}$ \\
\hline An. sergenti & 1203 & 0 \\
An. labranchiae & 144 & 0 \\
Total & 1346 & 0 \\
\hline
\end{tabular}

malaria transmission in these areas, verifying the efficiency of the malaria elimination strategy adopted by the Ministry of Health since 1998.

Nevertheless, Morocco is not immune from a resurgence of autochthonous malaria from dormant human reservoirs, which can always persist; the disease can reappear within 2 or 3 years. $P$. vivax is characterized by its very long incubation period [1]. Therefore, to maintain and reinforce the progress made so far, it is necessary to continue with the surveillance and prevention measures. The ELISA assays, which the entomology laboratory of the National Institute of Hygiene is now proficient in, should be integrated into the entomological surveillance phase of the national programme against malaria. The ELISA assay could be also of great use in surveillance and prevention of imported malaria by infected anopheles mosquitoes through international airports and ports.

\section{Acknowledgements}

This investigation received technical and financial support from the joint WHO Eastern Mediterranean Region (EMRO), Division of Communicable Diseases (DCD) and the WHO Special Programme for Research and Training in Tropical Diseases (TDR): The EMRO DCD/TDR Small Grants Scheme for Operational Research in Tropical and Communicable Diseases.

We gratefully acknowledge the staff of the entomology laboratory, M. Elkohli M. Elrhazi, L Laqraa, S. Ouahabi and N. Saaf, for technical assistance in the field and the laboratory. We also thank M. Amrou, A. Bounsir, M. Boumedian, A. Lyalli and M. Boutmime of the entomology service in Khouribga, Taounate, Chefchaouen and Al Hoceima provinces for help in collecting specimens. We thank Dr. D. Fontenille from IRD Montpellier for training in immunological techniques. We are grateful to $\mathrm{Dr}$ Robert Wirtz for providing documentation, advice and monoclonal antibodies.

\section{References}

1. Izri AM et al. Accès palustre à Plasmodium vivax plus de cinq ans après un séjour à Meknes, Maroc [Plasmodium vivax malaria seizure more than 5 years after a stay in Meknes, Morocco]. Bulletin de la societe de pathologie exotique, 1994, 87:189.

2. Wirtz RA et al. Identification of Plasmodium vivax sporozoites in mosquitoes using an enzyme-linked immunosorbent assay. American journal of tropical medicine and hygeine, 1985, 34(6):1048-54.

3. Wirtz RA et al. Field evaluation of enzyme-linked immunosorbent assays for Plasmodium falciparum and Plasmodium vivax sporozoites in mosquitoes (Diptera: Culicidae) from Papua New Guinea. Journal of medical entomology, 1987, 24:433-7. 
4. Gu WD. Estimating sporozoite rates by examining pooled samples of mosquitoes. Transactions of the Royal Society of Tropical Medicine and Hygeine, 1995, 89:359-60.

5. Stratégie d'élimination du paludisme au Maroc, plan et éléments d'évaluation [Strategy for the elimination of malaria in Morocco, plan and evaluation factors]. Rabat, Morocco, Ministère de la Santé, 2001:48.

6. Manual on practical entomology in malaria, Part I \& Part II. Geneva, World Health Organization, 1975.

7. Brhunes $\mathrm{J}$ et al. Les moustiques de l'Afrique méditerranéenne, logiciel d'identification et d'ensegnement [The mosquitoes of Mediterranean Africa, software for identification and training]. Montpellier/Tunis, L'Institut de recherche pour le développement/L'Institut Pasteur de Tunis, 2000.

8. Wirtz RA et al. Development and evaluation of an enzyme-linked immunosorbent assay for Plasmodium vivax VK247 sporozoites. Journal of medical entomology, 1992, 29:854-7.

9. Collins $\mathrm{FH}$ et al. Monoclonal antibodybased enzyme-linked immunosorbent assay (ELISA) for detection of Plasmodium malariae sporozoites in mosquitoes. American journal of tropical medicine and hygiene, 1988, 38:283-8.

\section{Two EMRO malaria publications}

The WHO Regional Office for the Eastern Mediterranean (EMRO) has recently brought out the following publications: Report on the responsiveness of the RBM programme to country needs in the WHO Eastern Mediterranean Region and Roll back malaria in the Eastern Mediterranean Region: achievements, challenges and the way forward.

The report presents the findings of an evaluation team which was established by EMRO to evaluate the responsiveness of the EMR Roll Back Malaria (RBM) programme to the needs of the countries in the Region. The general purpose of the evaluation was: to review the support and contribution provided by the EMR RBM programme to the malaria endemic countries of the Region; and to determine the progress being made by these countries to prevent and control malaria and in what ways the regional RBM programme can further help them to achieve their objectives.

Roll back malaria in the Eastern Mediterranean Region: achievements, challenges and the way forward is an advocacy document that addresses the past achievements of the programme. It highlights the various challenges facing the programme and looks at how these challenges can be met and overcome in the future.

Both publications can be obtained from: Distribution and Sales, WHO/ EMRO, Addul Razzak Al Sanhouri Street, PO Box 7608, Masr City, Cairo 11371, Egypt. Telephone: (202) 67025 35; Fax: (202) 67024 92/4. They are also available online at:http://www.emro.who.int/rbm/PDF/EMMAL-307-E.PDF and http://www. emro.who.int/rbm/PDF/MAL-305-E.pdf

المجلة الصحية لشرق المتوسط، منظمة الصحة العالمية، المجلد التاسع، العدد ع، ب... 